16 e 17 de agosto de 2018, centro de convenções da FCAV/UNESP - Câmpus de Jaboticabal, SP

\title{
CONTROLE DA MANCHA PRETA DO AMENDOIM UTILIZANDO DIFERENTES FORMULAÇÕES DE CLOROTALONIL ASSOCIADAS COM TRIAZÓIS E ESTROBIRULINA
}

Rodolfo Pires Ribeiro ${ }^{1}$, Jair Heuert ${ }^{2}$

${ }^{1}$ Engenheiro Agrônomo, Beatrice Comércio Importação e Exportação de Amendoim Ltda. Tupã-SP, e-mail rodolfopiresribeiro@gmail.com (Apresentador do trabalho); ${ }^{2}$ Engenheiro Agrônomo, Embrapa, Santo Antônio de Goiás-GO, jair.heuert@embrapa.br.

RESUMO: A mancha preta (Cercosporidium personatum) é a doença que mais afeta a cultura de amendoim, causando desfolha e grandes perdas na produtividade.Poucos fungicidas são registrados para a cultura, dificultando o manejo químico. O objetivo deste trabalho foi avaliar diferentes formulações de clorotalonil associadas com triazóis e estrobirulinas no controle desta doença, em ensaio de campo. O delineamento experimental utilizado foi de blocos casualizados, com três repetições e a cultivar Granoleico. Foram testados 11 tratamentos químicos: sem aplicação, clorotalonil, clorotalonil associado à diferentes concentrações e combinações de triazois e estrobilurinas. As pulverizações se iniciaram aos 25 dias após a semeadura com intervalos de 09 dias, totalizando 8 aplicações.A severidade foi quantificada avaliando 10 plantas por parcela, utilizando uma escala diagramática de nove notas. Também foi avaliada a produção no final do ciclo. Os tratamentos onde o clorotalonil estava associado à triazóis e estrobirulinas resultaram em menor severidade e maiores produtividades.

Palavras chaves: Cercosporidium personatum, controle químico.

\section{INTRODUÇÃO}

O amendoim (Arachis hypogaea L.) pode ser afetado por diversas doenças, e na parte área a maior severidade é causada pela mancha preta (Cercosporidium personatum) (COUTINHO; SUASSSUNA, 2014). A mancha preta geralmente aparece com maior intensidade na parte final do ciclo ocasionando redução da área foliar, queda prematura das folhas e consequentementediminuindo a produção. As lesões da mancha pretase caracterizam pelacoloração castanha escura na face superior do folíolo, arredondadas e com diâmetros variáveis. As esporulações do fungo ocorrem na parte abaxial das folhas e nas hastes as manchas são mais alongadas. (MORAES, 2006).

Entre as estratégias para diminuir a severidade da mancha preta, o controle químico se faz necessário para reduzir os prejuízos dessa doença, necessitando de oito a dez aplicações durante o ciclo (CULBREATH et al., 2009). Os fungicidasClorotalonil e os triazóis são eficientes no controle da mancha preta, além de apresentarem controle sobre outras manchas foliares (MORAES et al., 2001). As estrobilurinas compreendem uma categoria de produtos químicos mais recentes, com início do seu 
uso por volta do ano 1995 na cultura do amendoim. (CULBREATH et al., 2002). Em outros estudos mostram que a combinações entre estrobilurina, triazóis, mais Clorotalonil tem se mostrado uma estratégia eficiente no controle de mancha preta do amendoim ao longo do desenvolvimento da cultura, obtendo alta produtividade (RUAS, 2014; CORDEIRO JUNIOR et. al., 2017).

O objetivo foi para avaliar a eficiência de diferentes marcas comerciais de Clorotalonil existentes no mercado com associação a triazol com estrobilurina no controle de mancha preta do amendoim.

\section{MATERIAIS E METODOS}

O experimento foi instalado no município de Rancharia no estado de São Paulo. O ensaio foi instalado dia 22 de janeiro de 2018 em uma época considerada de maior incidência de doenças, já que a semeadura normal se inicia em meados de outubro. O delineamento experimental utilizado foi o de blocos casualizados com três repetições, as parcelas eram compostas por quatro linhas de cinco metros de comprimento.

Tabela 1. Fungicidas e seus ativos, respectivas concentrações e doses, avaliados para o controle químico da mancha preta da cultura do amendoim, Rancharia - SP, safra 2017/2018.

\begin{tabular}{|c|c|c|}
\hline $\begin{array}{l}\text { Nome } \\
\text { Comercial }\end{array}$ & Ativo & Dose \\
\hline Bravonil 720 & CLOROTALONIL (720 g/L) & $2,06 \mathrm{~L} / \mathrm{ha}$ \\
\hline Nillus & CLOROTALONIL (500 g/L) & $2,98 \mathrm{~L} / \mathrm{ha}$ \\
\hline Fezan Gold & CLOROTALONIL $(450 \mathrm{~g} / \mathrm{L})+$ TEBUCONAZOLE $(50 \mathrm{~g} / \mathrm{L})$ & $3,30 \mathrm{~L} / \mathrm{ha}$ \\
\hline Ichiban & CLOROTALONIL (720 g/L) & $2,06 \mathrm{~L} / \mathrm{ha}$ \\
\hline Glider & CLOROTALONIL (720 g/L) & $2,06 \mathrm{~L} / \mathrm{ha}$ \\
\hline $\begin{array}{l}\text { Bravonil } 720+ \\
\text { Opera }\end{array}$ & $\begin{array}{l}\text { CLOROTALONIL }(720 \mathrm{~g} / \mathrm{L})+ \\
\text { PIRACLOSTROBINA }(133 \mathrm{~g} / \mathrm{L})+\text { EPOXICONAZOL }(50 \mathrm{~g} / \mathrm{L})\end{array}$ & $2,06 \mathrm{~L} / \mathrm{ha}+0,6 \mathrm{~L} / \mathrm{ha}$ \\
\hline Nillus + Opera & $\begin{array}{l}\text { CLOROTALONIL }(500 \mathrm{~g} / \mathrm{L})+ \\
\text { PIRACLOSTROBINA }(133 \mathrm{~g} / \mathrm{L})+\operatorname{EPOXICONAZOL~}(50 \mathrm{~g} / \mathrm{L})\end{array}$ & $2,06 \mathrm{~L} / \mathrm{ha}+0,6 \mathrm{~L} / \mathrm{ha}$ \\
\hline $\begin{array}{l}\text { Fezan Gold }+ \\
\text { Opera }\end{array}$ & 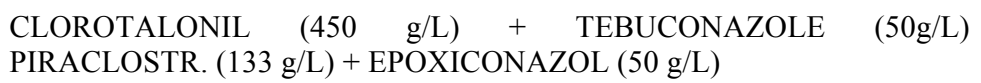 & $3,30 \mathrm{~L} / \mathrm{ha}+0,6 \mathrm{~L} / \mathrm{ha}$ \\
\hline Ichiban + Opera & $\begin{array}{l}\text { CLOROTALONIL }(720 \mathrm{~g} / \mathrm{L})+ \\
\text { PIRACLOSTROBINA }(133 \mathrm{~g} / \mathrm{L})+\operatorname{EPOXICONAZOL~}(50 \mathrm{~g} / \mathrm{L})\end{array}$ & $2,06 \mathrm{~L} / \mathrm{ha}+0,6 \mathrm{~L} / \mathrm{ha}$ \\
\hline Glider + Opera & $\begin{array}{l}\text { CLOROTALONIL }(720 \mathrm{~g} / \mathrm{L})+ \\
\text { PIRACLOSTROBINA }(133 \mathrm{~g} / \mathrm{L}) .+ \text { EPOXICONAZOL }(50 \mathrm{~g} / \mathrm{L}\end{array}$ & $2,06 \mathrm{~L} / \mathrm{ha}+0,6 \mathrm{~L} / \mathrm{ha}$ \\
\hline Testemunha & - & - \\
\hline
\end{tabular}

O cultivar de amendoim utilizado foi o Granoleico, que possui porte rasteiro, é amplamente cultivada na região, sendo porém suscetível à mancha-preta (RIBEIRO et. al., 2017). O espaçamento usado foi $0,9 \mathrm{~m}$ com 17,6 plantas por metro linear; cada parcela tinha 18 metros quadrados. As 
aplicações foram realizadas com pulverizador costal elétrico com vazão constante de 200 litros por hectare, com intervalo de aplicação de 09 dias.

A avaliação de severidade foi realizada em 10 plantas por parcela aos 120 dias após a semeadura usando a escala diagramática da incidência da mancha preta com notas de 1-9. (SUBRAHMANYAM et. al., 1982). A produtividade foi avaliada aos 125 dias após a semeadura, em dois metros lineares das duas linhas centrais de cada parcela.

Os dados foram submetidos à análise de variância pelo teste $\mathrm{F}$, para efeito de significância dos tratamentos e as médias comparadas pelo teste de Scoot Knott a 5\% de probabilidade.

\section{RESULTADOS E DISCUSSÃO}

Observou-se um aumento dos sintomas visuais de mancha preta do amendoim ao longo do ciclo de desenvolvimento vegetativo e reprodutivo da cultura no tratamento testemunha, na qual não recebeu aplicações de fungicidas, constatando-se a alta susceptibilidade da cultivar Granoleico a esta doença foliar (Tabela 2).

Tabela 2. Notas de sintomas de mancha preta da cultura do amendoim, em função dos diferentes tipos de fungicidas, Rancharia - SP, safra 2017/2018.

\begin{tabular}{llllll}
\hline Fungicidas & \multicolumn{2}{l}{ Notas de severidade } & $\begin{array}{l}\text { Produtividade } \\
\mathrm{kg} / \mathrm{ha}\end{array}$ & & Sacas/Alqueire \\
\hline Fezan Gold + Opera & 5,01 & $\mathrm{~A}$ & $6.546,29$ & $\mathrm{a}$ & 633,68 \\
Glider + Opera & 5,16 & $\mathrm{~A}$ & $6.388,88$ & $\mathrm{a}$ & 618,44 \\
Glider & 5,69 & $\mathrm{~B}$ & $6.314,81$ & $\mathrm{a}$ & 611,27 \\
Fezan Gold & 5,35 & $\mathrm{~A}$ & 6.194 .44 & $\mathrm{a}$ & 599,62 \\
Ichiban + Opera & 5,25 & $\mathrm{~A}$ & 6.185 .18 & $\mathrm{a}$ & 598,73 \\
Ichiban & 5,66 & $\mathrm{~B}$ & $6.185,18$ & $\mathrm{a}$ & 598,73 \\
Nillus + Opera & 5,34 & $\mathrm{~A}$ & $6.148,14$ & $\mathrm{a}$ & 595,14 \\
Nillus & 5,89 & $\mathrm{~B}$ & $5.935,18$ & $\mathrm{~b}$ & 574,53 \\
Bravonil + Opera & 5,36 & $\mathrm{~A}$ & $5.907,40$ & $\mathrm{~b}$ & 571,84 \\
Bravonil 720 & 5,74 & $\mathrm{~B}$ & 5.842 .59 & $\mathrm{~b}$ & 565,56 \\
Testemunha & 8,63 & $\mathrm{C}$ & $5.074,07$ & $\mathrm{c}$ & 491,17 \\
\hline F tratamentos & 126,10 & & 9,01 & & - \\
\hline CV $(\%)$ & 3,10 & & 4,29 & & - \\
\hline
\end{tabular}

Médias seguidas de mesma letra minúsculas na coluna não diferem entre si pelo teste de Scoot $\operatorname{Knott}(\mathrm{p} \geq 0,05) .{ }^{* *}$ significativo a $1 \%$ de probabilidade. 
As menores notas foram encontradas nos tratamentos: Fezan Gold + Opera, Glider + Opera, Fezan Gold, Ichiban + Opera, Nillus + Opera, Bravonil 720 + Opera, com uma média de 5,24. Nestes tratamentos o Clorotalonil estava associado com uma mistura.

Nos tratamentos Glider, Ichiban, Bravonil 720 e Nillus, onde o ingrediente ativo era apenas o Clorotalonil a média das notas de severidade ficou com média de5,74. A aplicação de Clorotalonil associado a uma mistura melhora a eficiência no controle de mancha preta. A testemunha ficou com uma média 8,63.

A média da produtividade foi do ensaio foi de6.065,65 Kg/ha ${ }^{-1}$. As maiores produtividades foram encontradas nos seguintes tratamentos: Fezan Gold + Opera, Glider + Opera, Glider, Fezan Gold, Ichiban + Opera, Ichiban e Nillus + Opera. No tratamentoFezan Gold + Opera foi constatado visualmente que ocorreu fitotoxidez em algumas folhas ocasionado devido aos dois triazóis usados na mistura (Tebuconazole e Epoxiconazol).

\section{CONCLUSÃO}

Houve redução dos índices de severidade quando o Clorotalonil foi aplicado em misturaao Opera (Piraclostrobina + Epoxiconazol), no caso Fezan Gold (Clorotalonil + Tebuconazole) e Fezan Gold + Opera (Clorotalonil+ Tebuconazole) + Piraclostrobina + Tebuconazole).

As melhores produtividades foram obtidas nos seguintes tratamentos: Fezan Gold + Opera, Glider + Opera, Glider, Fezan Gold, Ichiban + Opera, Ichiban e Nillus + Opera.

\section{AGRADECIMENTOS}

Os autores prestam seus agradecimentos aos produtores Romildo Ramos Contelli e Nilson Ramos Contelli, aos agrônomos que contribuíram na condução do ensaio: Leandro Cesar Cusim dos Santos -El Carmen sementes do Brasil;Rodrigo Aparecido Iorino - Agrofértil - Tupã-SP; Renan da Silva Bonetto Vieira - Agrofito Basf; José Roberto Engelesberger - Agrofito - Tupã-SP; Mauricio Lou Daneluti - Casul - Tupã-SP; Israel Ruiz Neto - Casul - Tupã-SP; Eduardo KazuoAoki Agrotekne - Tupã-SP. Também aos pesquisadores da Embrapa, Taís de Moraes Falleiro Suassuna e Nelson Dias Suassuna pelas orientações.

\section{REFERÊNCIAS BIBLIOGRÁFICAS}

CORDEIRO JUNIOR, P. S.; FINOTO, E. L.; MARTINS, M. H.; SOUZA, T.M. Eficiência de fungicidas no controle de mancha preta Cercosporidium personatum do amendoim na safra 2016/2017.Em: ANAIS DO ENCONTRO SOBRE A CULTURA DO AMENDOIM, 2017, Digital proceedings... Campinas, GALOÁ, 2018. Disponível em: https://proceedings.science/encontroamendoim-2017/trabalhos/eficiencia-de-fungicidas-no-controle-de-mancha-pretacercosporidiumpersonatumdo-amendoim-na-safra?lang=pt-br. Acessado em: 27/05/2018. 
COUTINHO, M. W; SUASSUNA, N. D. Sistemas de produção de amendoim: Manejo integrado de doenças.

Disponível

em:

https://www.spo.cnptia.embrapa.br/conteudo?p_p_id=conteudoportlet_WAR_sistemasdeproducaolf6 1 gal ceportlet\&p $p$ lifecycle $=0 \& p \quad p$ state $=$ normal\& $p \quad p$ mode $=v i e w \& p \quad p$ col $i d=$ column-

$1 \& p \_p \_c o l \_c o u n t=1 \& p \_r \_p \_-76293187 \_$sistemaProducaoId $=3803 \& p \_r \_p \_-$

996514994 topicoId=3452Acessado em 24/05/2017

CULBREATH, K.; STEVENSON, B. K.; BRENNEMAN, T. B. Management of late leaf spot of peanut with benomyl and chlorothalonil: A study in preserving fungicide utility. Plant Disease, St. Paul, p. 349 - 355, 2002a. Disponívelem: http://dx.doi.org/10.1094/PDIS.2002.86.4.349

CULBREATH, A.; BEASLEY, J.; KEMERAIT, R.; PROSTKO, E.; BRENNEMAN, T.; SMITH, N.; TUBBS, S.; PAZ, J.; OLATINWO, R.; TILLMAN, B.; GEVENS, A.; WEEKS, R.; HAGAN, A. Peanut update. Gainesville, 2009.

MORAES, S.A., GODOY, I.J., PEZZOPANE, J.R.M., PEREIRA, J.C.V.N.A.; SILVEIRA, L.C.P. Eficiência de fungicidas no controle da mancha preta e verrugose do amendoim por método de monitoramento. Fitopatologia Brasileira, v.26, p.134-140, 2001.

MORAES DE, S. A. Amendoim: Principais Doenças, Manejo Integrado e Recomendações de Controle. 2006. Artigo em Hypertexto. Disponível em: http://www.infobibos.com/artigos/2006_2/amendoim/index.htm. Acessado em: 24/05/2017.

RIBEIRO, R.P.; HEUERT, J.; SUASSUNA, N. D. e SUASSUNA, T. M. F; Desempenho de Linhagens de Amendoim sob alta severidade de doenças. Em: ANAIS DO ENCONTRO SOBRE A CULTURA DO AMENDOIM, 2017. Digital proceedings... Campinas, GALOÁ, 2018. Disponível em: https://proceedings.science/encontro-amendoim-2017/trabalhos/desempenho-de-linhagens-deamendoim-sob-alta-severidade-de-doencas-foliares?lang=pt-br.Acessado em : 01/06/2018

RUAS, A.R. Número mínimo de aplicações de fungicidas no controle das cercosporioses da cultura do amendoim. 2014. xi, 41 p. Dissertação (mestrado) - Universidade Estadual Paulista Júlio de Mesquita Filho, Faculdade de Ciências Agrárias e Veterinárias, 2014. Disponívelem: http://hdl.handle.net/11449/121910.

SUBRAHMANYAM, P.; MCDONALD, D.; GIBBONS, R. W.; NIGAM, S. N.; NEVILL, D.J. Resistance to rust and late leaf spot diseases in some genotypes of Arachis hypogaea. Peanut Science, v.9, p.9-14, 1982. 